\title{
R\&D Partnerships: an exploratory approach to the role of structural variables in joint project performance
}

\begin{abstract}
Traditionally the literature on partnership has focused on understanding why firms choose to cooperate and with whom, however, our understanding of the impact of the resulting network structure on the performance of the project is limited. This study builds on joint R\&D projects developed in Europe in order to analyse certain structural variables - number and typology of partners, and intensity and density of interactions in the network - which may result in a greater performance of exploration and exploitation R\&D projects. Findings show that these structural variables are good predictors of project performance; in particular, the joint performance function in exploration projects is positively dependent on the number of partners; however, in exploitation projects this function depends positively on the density and intensity of interactions, and negatively on the number of partners. Our results complement previous research while adding empirical evidence on the nonlinear and contingent character of structural variables and the performance of joint projects.
\end{abstract}

Keywords: Density; Intensity; Structure; Joint R\&D Projects; Partnerships.

\section{Introduction}

Technological collaboration for R\&D development is being increasingly adopted between organizations to combine resources for common goals [1-3]. Firms join other institutions in organising networks, not only at a local but also at a national and international level, in order to develop technological projects that may positively influence competitiveness [3-7]. The effect of network structure in technological project performance has been a topic of considerable interest and study in recent years [5-8]. According to Hagedoorn et al. [4], Pek-Hooi and Roberts [9] there are two elements which integrate the network structure of a joint R\&D project: The network nodes comprising the partners that take part in the project, and the interactions established among partners. Characterized by these two main elements, the study of network structures has been approached from two distinct points of view: The resource-based perspective where the analysis focuses on the partner whose role is to contribute and share resources in the network [10-16]; and the social capital theory, 
where the key variable is the interaction between partners, analysing those resources inherent in social relationships which facilitate the collective action [17-25], [6].

When studying joint R\&D projects, as March [26] points out, exploitation projects use existing information to improve efficiency and returns from present strategies, competencies and procedures, while exploration entails searching and experimenting to find emerging innovations which will produce future profits. Koza and Lewin [27, p. 256] subsequently argued that a partner's decision to enter in a joint project 'can be distinguished in terms of its motivation, to exploit an existing capability or to explore new opportunities'. From a structural point of view, previous studies have documented that cohesion, strong ties, and small sizes are the central characteristics of exploitation joint R\&D projects [27-28], [16]. On the other side, Gilsing et al. [29] have pointed out that the main characteristics of exploration joint $R \& D$ projects devoted to the search and exploration of technological information are their sparseness, weak ties, and large size.

Beyond the broad consensus of the importance of network structure in managerial performance [30-31], there is a debate on several issues regarding structural attributes and the mechanisms through which they impact on project performance. Thus, in the case of exploration projects, scholars suggest that the large size and weak ties of networks tend to create small groups (clustering) within the network, and that this has a negative impact on the performance of the joint project [29], [6], [32]. Regarding exploitation projects, other studies argue that strong cohesion in networks produces redundant information and small size increases the conflicts between partners [3].

In this paper we seek to further the debate on size and cohesion issues using survey data collected from a representative sample of joint $R \& D$ projects carried out within European Framework Programmes. Using both exploration and exploitation projects from these Programmes we address three questions: (1) Is there an optimal structure for networks in joint R\&D projects for the two types of projects considered?; if this is true, (2) what typology and number of partners must be involved in exploration and exploitation joint R\&D projects to maximise network performance?; and (3) what class of interactions must be established in exploration and exploitation R\&D projects to maximise 
network performance? In this article we develop a combined methodology - structural equation modelling and artificial neural networks (ANN) - to test causal relationships and approximate the joint performance function of exploration and exploitation $R \& D$ projects.

The purpose of our study is to contribute to the extant research on project literature in two ways. First, we aim to extend our understanding of the effects and influence of structural variables on the performance of project networks. Second, we aim to contribute to project management literature by analysing the structural variables which are central in explaining efficient performance in exploitation and exploration joint $\mathrm{R} \& \mathrm{D}$ projects.

In the sections that follow, we present a concise overview of relevant literature on the structure of joint R\&D projects in order to generate research questions. Subsequently, we present the findings obtained from the empirical analysis carried out using a sample of joint $R \& D$ projects developed in the European biotechnology industry. We conclude with a discussion of our findings, implications, limitations, and suggestions for further research.

\section{Theoretical background}

\subsection{Joint R\&D projects: Objectives and Structure}

Joint projects are the union of two or more partners through a cooperative agreement with the purpose of sharing capabilities and resources to reach a joint objective [33], [8]. The set of activities developed in the joint $R \& D$ project create multiple interactions among the partners in the dynamic process which lead to the accomplishment of project objectives. Pek-Hooi and Roberts [9] pointed out that technological process are those processes which are distributed among all agents involved in the network, whilst Scott-Young and Samson [34] indicated that an organisational structure is necessary for the development of the joint project. The objective of this structure is to infuse order in a relationship where potential conflict may arise, and where opportunities for common gain exist [35], [36]. The structure, therefore, is the framework within which the R\&D process is developed and the partnership is organised. This structure, generally a network structure, is made up of the nodes (the 
partners), and the interrelated links or ties among them [25]. In both the determination of the partners as well as in the ties, the objective is that the resulting design shall be efficient and achieve the expected joint performance [24], [36], [31]. Therefore, it can be argued that different combinations of partners and ties may result in different levels of performance within networks which share the same objectives.

\subsection{Resource-based Perspective: Typology of partners and size of network}

From the resource-based perspective, collaboration to develop a joint $R \& D$ project is a way to access technological resources or to improve competitive positioning without the need to acquire or possess them through traditional paths [11], [15], [16]. The strategic advantage of partnership derives from specific assets that firms dedicate to cooperation relationships, and from complementarities between their own resources and the resources of their partners. Thus, one of the main aspects of the structural design of the network, from the firm viewpoint, is the definition and search for a suitable partner profile to achieve the results sought through the cooperation. Questions such as why to cooperate and with whom, have been key variables for scholars in those analyses [3],[15]. However, less attention has been paid, from the project perspective, to the definition of the project structure and its impact on project results. One view is that advanced by Dyer and Nobeoka [27] who identified two kinds of networks in the case of Toyota's suppliers. The first type was made up of a large number of partners whose objective was to explore technological information. In this case, the large number of partners increased the sources of knowledge. The second comprised a smaller number of partners whose objective was to use technological information to generate innovative products, that is, to exploit knowledge and information. Their results confirm the hypothesis that each type of project has distinctive structural characteristics. From the viewpoint of project results, Gilsing et al. [29] pointed out that the objective of exploration projects is to create technological knowledge through a constant search for new opportunities. According to these authors, the search for new opportunities implies that exploration projects normally include universities and research centres from different countries, as well as a high number of participants. Exploitation projects on the other hand, involve companies, 
universities or consultants with a high heterogeneity of partners, but fewer in number than in the case of research exploration projects, and seek to engage both sources of innovation (universities) as well as users (firms) [9]. In general, exploitation projects are characterised by their smaller size structure and greater diversity of partners than in exploration projects,

Efficiency in the structure, however, has not been specified in the literature in terms of number of partners and their types, and in this sense there are discrepancies. While Emerson [37] suggested that having more contacts creates greater alternatives for obtaining valued resources and more ideas, Burt [38] noted that size is a mixed blessing. Thus, in the organisational efficiency of joint projects, some researchers point out that when the number of partners is high, clustering and non-cohesion result in inefficiencies in the operation of exploration projects [38], [28]. In the same sense, in exploitation projects, when the number of partners is low, the risks reside in the lack of motivation due to the burden of the project for each partner, and in the difficulties in obtaining resources [39],[16], [40], [41].

Regarding the type of partners involved in the structure of the network, researchers have pointed out that exploration projects formed only by universities and/or research centres run the risk of obtaining less applied or innovative results [9], [42]; however, greater diversity in the type of partners involved in the projects may not lead to a shared vision that provides a common understanding of the collective objectives and the proper ways to act within the network [43]. Moreover, other problems such as lack of communication between partners, the lack of mutual understanding, and other cultural failures, may result in inefficiencies [44], [39], [36], [45]. These are classic risks inherent in the cooperation between universities and firms which, in general, generate inefficiencies in the project performance [45].

Consequently, to the extent that large networks can be difficult to maintain and may experience diminishing performance, managers need to balance their size and type of partners to achieve the network's objectives. From the foregoing, we formulate the following questions: 
Research Question 1a: In order to maximise the joint performance, what is the optimal size of the network in exploration joint $R \& D$ projects?

Research Question 1b: In order to maximise the joint performance, what is the optimal size of the network in exploitation joint $R \& D$ projects?

Research Question 2a: In order to maximise the joint performance, what typology of partners will be required to participate in exploration projects?

Research Question 2b: In order to maximise the joint performance, what typology of partners will be required to participate in exploitation projects?

\subsection{Social Capital Perspective: Interactions in networks}

Interactions among partners involved in the project comprise the second structural element of joint R\&D projects. Granovetter [46] defined interaction as a combination of the duration of the tie itself, emotional intensity, intimacy or mutual confidence, and reciprocal services between the partners. The interactions among the partners have been thoroughly discussed in the social capital literature which has been concerned with understanding how interaction affects individual 'exchange' and 'transactional behaviour' [19]. These works, as Borgatti and Foster [47] pointed out, have resulted in two streams of research. In the first, from the focus of individual exchange, the analysis of network structure centres on the quality of the constituent ties -their frequency, intensity and multiplexity-, and the role of ties as structures of information exchange. Thus, interactions between partners constitute an important source of information and resources for participants in the project. In this sense, Granovetter [46], Rowley et al. [48], argued that weak ties are conduits through which partners can access novel information, while Borgatti and Halgin [25] indicated that strong ties are the appropriate channel for transferring tacit knowledge.

The second stream of research focuses on interactions as a transactional behaviour structure stressing that ties develop a shared understanding of the utility of certain behaviours. Uehara [19] points out that this is a result of discussing opinions in highly socialised relationships which, in turn, 
influence the actions of partners. Coleman [18] argued that closure or dense network structure- the extent to which actors' contacts are connected- facilitates the emergence of effective norms and maintains the trustworthiness of others, thereby strengthening social capital. In contrast with Coleman's focus on closure or dense networks, Burt [38] argued that a sparse network with few redundant ties often provides greater social capital benefits. Granovetter [49] concluded that dense or sparse ties affect the quality of relationships between actors.

From an integrated point of view, Borgatti and Foster [47] emphasized that both approaches are elaborations of the same theory, and that an interesting piece of investigation is the exploration of how structural differences alone affect the performance of networks. In the same sense Granovetter [46], Burt [38], and Rowley et al. [48] stressed that strength/weak ties and dense/sparse networks are central in the study of network performance.

It is generally accepted that interactions have a significant impact on project performance. However, this is a complex relationship and it is not clear exactly how interactions influence project performance [50-52]. Thus, while Coleman [18] argued that the structure of the network allows the partners to access different types of information, a potential drawback to the strength of relations is that through repeated interactions, the exchange partners become more alike and develop similar stocks of knowledge; Burt [38] pointed out the benefits of access to non-redundant contacts in order to obtain novel information. Some authors have documented that a highly cohesive network implies that partners may be exposed to too much information, leading to cognitive overload and poorer work performance [53], [22], [6]; others have also supported the idea that these increased social interactions may not be associated with parallel increases in outcomes [54], positing a not strictly linear relationship in which initially lower-intensity contacts are expected to benefit from significant effects in a linear form, although increasing relationship strength will lead to diminishing or negative returns. As McFadyen and Cannella [55] pointed out, social interactions involve the costs associated with the time, energy and attention needed to establish and maintain relationships. This is especially true for exploration projects, when the low level of contract definition needs to be compensated by a certain 
level of cohesion in order to create social norms for a more efficient exchange [56]. Therefore, taking the arguments above, we address another two research questions.

Research Question 3a: In order to maximise the joint performance, what type of interactions will be required for exploration joint $R \& D$ projects?

Research Question 3b: In order to maximise the joint performance, what type of interactions will be required for exploitation joint $R \& D$ projects?

\section{Conceptual model}

We consider that joint $R \& D$ projects are supported within structural networks. A structural network is a set of points, called nodes or vertices, with connections between them, called links or ties. In the context of joint $R \& D$ projects, each partner is considered to be a node of the network which has its own distinctive contribution to the whole network- and the interactions among partners are contemplated as the ties that link them to each other. As we have discussed, depending on the objectives of the joint $R \& D$ project the structural network will be different. Thus, the number and the typology of partners as well as the interactions between partners may vary.

We analysed the number of nodes in the network or the network size $(N)$ and the typology of these nodes/ partners. Given the difficulty to individually analyse the different combinations of partners into each network, we use the Gini coefficient dispersion degree of partners $\left(G_{p}\right)$ to measure the higher or the lower homogeneity/heterogeneity among the partners taking part in the network.

For interactions materialised by the ties, we analysed two variables that characterize interactions in a network: the intensity of the tie, and the density of the network. Intensity of the tie (I) measures the frequency of contacts between two agents. Hence, the network may have strong ties if the frequency of contacts is high and weak ties if that frequency is low. The underlying hypothesis is that the higher the frequency of contacts, the higher the exchange of resources between agents will be. The second variable, density of the network $(D)$ refers to the number of contacts or interrelations established among the agents in the network. Thus, depending on this variable networks may be dense if there are 
a high number of contacts among all agents, and sparse otherwise. This variable is a way to examine the extent of the network integration and determines the proportion of all possible links that are actually present in the network.

Having established this departure point we drew up the model of joint R\&D projects through a systemic approach in which a set of input variables are transformed through a transfer function into results or output variables, that is, $f: \mathrm{I} \rightarrow \mathrm{O}$.

As input variables (I) we considered the technological dimension of the R\&D project measuring the number of partners $(\mathrm{N})$, the dispersion degree of partners $\left(\mathrm{G}_{\mathrm{p}}\right)$, the density of network $\left(\mathrm{D}_{\mathrm{i}}\right)$, and the intensity of tie $\left(\mathrm{I}_{\mathrm{i}}\right)$. As output variable $(\mathrm{O})$ we measured the results of the joint project in terms of joint performance $(\delta)$.

$$
f_{\mathrm{r}}:\left(\mathrm{N}, \mathrm{G}_{\mathrm{p}}, \mathrm{D}_{\mathrm{i}}, \mathrm{I}_{\mathrm{i}}\right) \rightarrow \delta
$$

where $r$ is the kind of project considered, exploration or exploitation.

The joint performance $(\delta)$ quantifies the tradeoffs among different efficiency attributes $\left(x_{i}\right)$ by providing a single metric for the multiple dimensions of the efficient project profile. These inputs are the levels of achievement on all of the relevant attributes.

$$
\boldsymbol{\delta}=\sum_{i}^{n} \boldsymbol{a}_{i} \boldsymbol{u}_{i}
$$

where $a_{i}$ is the weight of the attribute $i$; and $u_{i}$ is the value associated with each attribute $x_{i}$, being

$$
\sum_{i}^{n} a_{i}=1
$$

Given a joint project with two possible structures, the structure of the project $i$ is more efficient than the structure of the project $j$, when:

$$
\boldsymbol{\delta}_{\boldsymbol{i}}\left(\mathrm{N}_{\mathrm{i}}, \mathrm{G}_{\mathrm{pi}}, \mathrm{D}_{\mathrm{i}}, \mathrm{I}_{\mathrm{i}}\right)>\boldsymbol{\delta}_{j}\left(\mathrm{~N}_{\mathrm{j}}, \mathrm{G}_{\mathrm{pj}}, \mathrm{D}_{\mathrm{j}}, \mathrm{I}_{\mathrm{j}}\right)
$$




\section{Data and methodology}

To test the above hypotheses, we rely on primary data obtained on the performance of joint R\&D projects through a mail survey conducted on a sample of partners taking part in projects developed in European biotechnology companies whose primary commercial activity fell within the definition of biotechnology as given by OECD. According to the European Association for Bio-industries, at the end of 2004 there were 2163 biotechnology companies in the eighteen European countries; as numerous companies are small organizations, in this sector partnering has gained in prevalence.

The sample size was selected at random by stratified sampling, proportional to groups of type of project (exploration/exploitation), and European country [57]. We have selected the projects formed by public and private European companies between 2000 and 2006. Since 2006, the industry experienced a marked increase in both European and US-European mergers and acquisitions, so that the effect of partner specific experience would be diluted. However, the selected time period is wide enough to track the experience of partners in joint $R \& D$ projects accurately, because all projects considered had finished and the data were consolidated.

The sample size was set at 500 companies for a confidence interval of $95 \%$ and a significance level of $5 \%$. Data were collected through a mail survey to the identified companies to obtain information concerning the characteristics of their participation in partnerships and the circumstances that had surrounded the formation and development of the joint project. Each questionnaire referred to the participation in a specific joint project, and a questionnaire being sent out for each identified joint project. Although the majority of the identified companies had participated in more than three partnerships, we restricted the number of questionnaires to two, each per type of project. The criterion used to choose the two partnerships was the importance of the project, measured by the total finance of the project.

Total Design Methodology was used to administer the mail survey [58]. The questionnaire was addressed to the company's CEOs and project managers. A total of 211 completed questionnaires were received from the first mailing. A second mailing was sent three months later and an additional 
89 questionnaires were received. After a telephone follow up process, 71 extra questionnaire replies were collected. 129 mailings were returned as undeliverable or uncompleted. We thus obtained a final sample of 371 usable responses (163 for project managers of exploration projects and 208 for project managers of exploitation projects). In order to test the potential for non-response bias, we compared key attributes of respondents to those of the targeted population sample by employing t-test and ANOVA analysis between different mailing states. The results of the t-test for size $(p=0.27 ; p=$ 0.33 ), and country origin ( $p=0.29 ; p=0.31)$, revealed no significant differences between respondent and non-respondent groups. Moreover, we also compared first-, second-, and third-wave respondents by using ANOVA analysis. The results showed that there was no significant difference between the three groups in terms of the two measures.

\subsection{Measurement scales}

\section{Input variables measures}

Following Contractor and Monge [59], we analysed the number of nodes in the network, or the network size $(\mathrm{N})$, and the heterogeneity of these nodes/ partners. Thus, network size measures the number of partners participating in the network, that is, those partners who have a contractual relationship with the network [60].

Heterogeneity is the most direct indicator of the diversity of partners that the network contacts within its environment. Following Chiesa and Manzini [61], partner organisations were distinguished according to the following types: universities, research centres, and industries. Each partner typology was determined by its frequency of participation in the network and measured by a Likert scale from 1 (low) to 7 (high frequency). Given the difficulty of analysing the different combinations of partners in each network individually, we use the Gini coefficient dispersion degree of partners $(\mathrm{Gp})$ to measure the degree of homogeneity/heterogeneity among the partners taking part in the network, which ranges between 0 (heterogeneity of partners) and 1 (homogeneity of partners). 
For interactions materialised by the ties, consistent with the literature and a number of previous empirical studies [62], [19], [59], [47], we analysed two variables that characterise the degree of interactions in a network: the density of the network and the intensity of the tie,

Density of the network (D) describes the overall level of interaction reported by network members. This measure is based on previous works [62], [59] and on Borgatti and Cross's [63] definition of the network density as the ratio of the number of existing ties in the ego network (other than those involving the focal partner) divided by the total possible number of ties among its partners if each partner were linked to every other partner. Thus, networks are considered dense if all or a great part of their nodes are interconnected and sparse if they are not. The scale ranges from 1 (sparse network) to 7 (dense network).

Intensity of the tie (I) measures the strength or weakness of the relationship between two partners [62-63]. Following Reagans and McEvily [64], we used two variables to measure the tie strength, the emotional closeness and communication frequency. We measured these variables by Likert-type items: (1) How close are you with the project partners (no relationship, especially distant, distant, less than close, close, especially close, permanent)? (2) On average, how often do you talk to the project partners (hardly ever, yearly, quarterly, monthly, weekly, daily, permanent)? Thus, values near 7 imply that maximum strength of the tie is perceived by the partner; and the opposite if the values are near to 1 .

\section{Measure of the dependent variable}

The dependent variable, joint performance $(\delta)$, measures the probability of successful performance of exploration and exploitation joint R\&D projects. As described in the works of Krishnan and Martin [65] and Olk [66], we used a perception measure whose inputs are the levels of achievement on all of the relevant attributes of the project: time, budget, and results. Its output is measured in units of "performance", where less is better in the case of time and budget, and more is better in the case of results. Hence, to evaluate this variable, following the works of Krishnan and Martin [65] and Olk [66], we used a perception measure the joint performance $(\delta)$ whose inputs are the levels of 
achievement on all of the relevant attributes of the project: time $\left(x_{1}\right)$, budget $\left(x_{2}\right)$, and results $\left(x_{3}\right)$. To form this measure, we asked partners in each particular joint $R \& D$ project their perceptions of how the project was performed. The Likert scale, from 1 to 7 , reflected: (1) The extent to which the partners were satisfied with the overall results of the project; (2) The partners' satisfaction with respect to the project schedule; and (3) The extent to which the partners were satisfied with the financial performance of the joint project. We calculated the joint performance $(\delta)$ by multiplying each attribute's value by its weight (assuming $a_{i}=1 / 3$ ); and adding them in a weighted sum. Thus, values near 7 imply that joint performance perceived by the partner is maximum; and the opposite if the values are near to 1 .

\section{Analysis}

We carried out a pre-test using a structural model to determine the effect of each input variable on the output variable. Analysis of reliability from each indicator for these constructs has been tested by Cronbach alphas, which are above the desired threshold level of 0.7 . Thus, we can accept the validity of the constructs. Additionally, we tested our measurement model with the results showing a good fit for the exploration data $\left(\chi^{2}=70.276\right.$; d.f. $=53 ; \mathrm{p}<0.01$; incremental fit index (IFI) $=0.92$; Tucker Lewis index $(\mathrm{TLI})=0.90$; goodness-of-fit index $(\mathrm{GFI})=0.93$; comparative fit index $(\mathrm{CFI})=0.98$; root mean squares residuals $(\mathrm{RMR})=0.05$; and root mean square error of approximation $(\mathrm{RMSEA})=$ 0.08 , and for the exploitation data $\left(\chi^{2}=81.107\right.$; d.f. $=62 ; \mathrm{p}<0.01 ; \mathrm{IFI}=0.91 ;$ TLI $=0.90 ;$ GFI $=$ 0.91; $\mathrm{CFI}=0.95 ; \mathrm{RMR}=0.08$ and $\mathrm{RMSEA}=0.11)$. Table 1 presents the descriptive statistics, Pearson correlation and reliability coefficients for all variables used in this study.

-Insert Table 1 about here-

The structural model presents the results of our estimation in the following form:

$$
\boldsymbol{\delta}_{\mathbf{r}}=\boldsymbol{\beta}_{\mathbf{0}}+\sum_{i} \boldsymbol{\beta}_{\mathbf{i}} \mathbf{X}_{\mathbf{i}}
$$


where $\delta$ is joint performance, $r$ is the type of project considered, exploration or exploitation; $X_{i}$ represents the independent variables, the coefficient $\beta_{0}$ is the estimated constant, and $\beta_{i}$ the regression coefficients. To test the validity of the proposed model, we estimated three different model specifications (Tables 2 and 3). Models 1 and 1 ' contain dependent variables ( $\boldsymbol{\delta}$ exploitation/exploration) as a function of the number of partners $(\mathrm{N})$, and the dispersion degree of partners $\left(\mathrm{G}_{\mathrm{p}}\right)$. Models 2 and 2' capture the dependent variables ( $\boldsymbol{\delta}$ exploitation/exploration) as a function of the density of network (D), and the intensity of the tie (I). Models 3 and 3' contain the dependent variables ( $\boldsymbol{\delta}$ exploitation/exploration) as a function of the number of partners $(\mathrm{N})$, the dispersion degree of partners $\left(\mathrm{G}_{\mathrm{p}}\right)$, the density of network (D), and the intensity of the tie (I). Model fits are acceptable with significant chi-square values $(\mathrm{p}<0.01)$ for all models. Also, in Tables 2 and 3 we show the results obtained for the indexes IFI, TLI, GFI, CFI, RMR and RMSEA in the models, which are sufficiently close to the generally acceptable levels. Obtaining an acceptable level of fit suggests that the proposed model explains or fits the data quite satisfactorily. In order to evaluate a path between variables, significant positive relationships were found between input and output variables $(\mathrm{p}<0.05)$.

-Insert Tables 2 and 3 about here

\subsection{The design of the artificial neural network}

We represented both exploration and exploitation performance functions using the ANN model. Following Hornich et al. [67], we chose the Multilayer Perceptron (MLP) as the specific neural architecture for this case. The results of the representation allowed the study of optimisation points for which each performance function was maximised, and the determination of the input variable impact on the joint performance.

Following the suggestions from Ciurana et al. [68], the correct structure was selected after having tested the ANN-MLP configurations with different numbers of hidden layers, different numbers of neurons for each level, and different activation functions (see Table 4). It is observed that an increase 
in the number of layers within an ANN-MLP leads to a decrease in the estimated efficiency and accuracy in the two types of projects considered.

---Insert Table 4 about here-

-Insert Figures 1 and 2 about here-

Therefore, the configuration of our ANN-MLP model for exploration and exploitation projects was defined for 4-4-1, which means that there are 4, 4, and 1 neurons in the input, hidden and output layers respectively, with sigmoid and linear functions as activation functions.

Hence, the functional form for the joint performance is as follows:

$$
\delta=h\left(\sum_{k=1}^{4} \alpha_{k} \cdot g\left(\sum_{j=1}^{4} \beta_{j k} \cdot X_{j}\right)\right)
$$

where $X_{j}$ represents the input variables; $j$ the number of input variables; $h($.$) and g($.$) the sigmoid$ and linear activation functions; $\alpha_{k}$ and $\beta_{j k}$ the input and hidden network weights, respectively; and $k$ the number of hidden layers.

We tested the ANN-MLP architecture network for 163 input dates in exploration and 208 in exploitation projects. The results of our analysis showed that the ANN-MLP network output had a correlation coefficient of about 0.851 for exploration and 0.917 for exploitation with the actual outputs, which means a good fit of the ANN-MLP network model.

We have drawn the joint performance functions with a 2D representation. We used NeuroXL from Excel to show the relationship between the different input and output variables as displayed by Figures 3, 4, 5 and 6 in the case of exploitation/exploitation projects. Joint performance is represented as a function of the network size $(\mathrm{N})$, dispersion degree of partners $(\mathrm{Gp})$, density of the network (D), and intensity of ties (I). 


\section{Results}

The effect of input variables on joint performance for both types of projects is reflected in the structural model (Tables 2 and 3). The graphical representations in Figures 3, 4, 5 and 6, show the variability of joint performance $\delta$ with the structural variables size, partner typology, density, and intensity, and the impact and the form of this variation.

In the case of the influence of network size on joint performance, our results show a significant impact in both types of projects considered but with a different sign, as shown in structural models (see Tables II and III). While the size has a positive character $(\mathrm{p}<.001)$ in exploration projects, it affects negatively $(\mathrm{p}<.001)$ in exploitation projects. The neural network representations show that joint performances have a concave form, whereby we can affirm that a maximum or efficiency point exists. The efficiency point of the network in the case of exploitation projects is reached when the number of partners ranges from 4 to 7 (joint performance, $\delta \approx 5$ ) as shown in Figure 3 . In the case of exploration projects, however, the efficiency point is reached when the number of partners ranges from 14 to 20 (joint performance, $\delta \approx 3$ ) as shown in Figure 3. The graphical representation of the ANN displayed in Figure 3 shows how joint performance in the case of exploitation projects has a greater variation when the number of partners varies. Thus, a maximum in joint performance is reached when 4 or 5 partners take part in the network, which Hagedoorn [69] has denoted as the 'minimum to cooperate'. From that value on, joint performance moderately decreases until the number of partners reaches 8 or more, where it then decreases very quickly. In the case of the exploration projects, the representations show that joint performance moderately increases until the number of partners reaches 20 , where it then remains at the maximum value.

In the case of the dispersion of the partners, structural models show a significant relationship with the joint performance. While the dispersion of partners has a positive character $(p<.05)$ in exploration projects, this variable negatively affects $(\mathrm{p}<.01)$ exploitation projects. If we observe the neural network representations (Figure 4) we obtain similar results for the variable represented. These 
results indicate that a higher homogeneity in the typology of partners has a positive incidence in the performance of the exploration projects, while in the case of exploitation projects this result implies that the higher homogeneity in the typology of partners has a negative impact on the perceived performance of the project. The value which maximises joint performance, as observed in Figure 4 in the case of exploration projects, increases until reaching a maximum (joint performance, $\delta \approx 2$ ), when the typology of partners is homogeneous (dispersion degree near to 1). Similarly, Figure 4 shows, in the case of exploitation projects, a decreasing function, reaching the maximum (joint performance, $\delta \approx$ 1.7) for values of the partner dispersion degree near to 0 , that is, when partners are highly heterogeneous.

Network density and intensity of ties have a significant impact on joint performance but with a different sign as a function of the type of the project, as shown in the structural model (see Tables 2 and 3). In exploration projects, intensity $(\mathrm{p}<.05)$ and density $(\mathrm{p}<.05)$ have a negative character which means that the frequency of contacts among partners, the level of resources committed to the project and the interconnection between the participating partners are not important. Regarding the impact of density and intensity in exploitation projects, the structural model shows that these two variables have a positive and significant impact $(\mathrm{p}<.001)$. The structural model and the neural network representation show similar results. In fact, the neural network representations in both cases show that joint performance has a concave form, whereby we can affirm that a maximum or efficiency point exists. Thus, the efficiency point of the network in the case of exploitation projects is reached when the value of density ranges from 4 to 5 (joint performance, $\delta \approx 3.5$ ) as shown in Figure 5. In the case of exploration projects, however, the efficiency point is reached when the value of density is 2 (Joint performance, $\delta \approx 1.5$ ) as shown in Figure 5 . In the case of intensity, the efficiency point of the network in the case of exploitation projects is reached when this value ranges from 3 to 5 (joint performance, $\delta \approx 5$ ) as shown in Figure 6 . In the case of exploration projects however, the efficiency point is reached when the value of density falls near 2 (joint performance, $\delta \approx 2.5$ ) as seen in Figure 6. We can conclude from the representation that high levels of intensity in the interactions 
and dense networks in the configuration are very important variables in exploitation projects; when the density of the network and intensity of interactions are low, there is a significant and negative decrease in the perceived performance of exploration projects.

\section{Discussion and conclusion}

\subsection{Results summary}

The empirical results support that there is an optimal structure for networks in joint R\&D projects for the two types of projects considered. As regards the number of partners, it is observed that the joint performance function in exploration and exploitation projects exhibits a marked concavity. These two functions have in common that both are increasing, which means that the increase in the number of partners makes a positive marginal contribution to the joint performance of the $R \& D$ project. This outcome is consistent with the results from Grewal et al. [70, p. 1045] which highlighted that in projects 'the complex task can be spread over more developers, resulting in better organization, and hence higher productivity'. Moreover, because of the concave function, while new agents keep joining the network the increase in the joint performance function is lower (decreasing returns to scale) until those new partners generate a negative increase in the function. This result complements recent studies on the performance of networks in which the authors found that the incorporation of new partners in an existing network produces redundant resources and capacities, which is emphasised through decreasing marginal returns and the worsening of the relationship between contributions and payoffs [71].

Observing the differential aspects of performance functions, our results are consistent with prior research on exploitation activities [32], [28], which emphasizes that exploitation projects imply an improvement of the skills or the obtaining of resources which are characterised by the immediacy of their implementation. On the other hand, exploration activities as pointed out by March [26] imply the search for new information, with low immediacy and applicability, and in most cases characterised by greater uncertainty in terms of both the results as well as time, which makes the perception of their 
performance in the short term lower than in the case of exploitation projects [28]. Hence, we may conclude that the optimum perceived in network performance functions is conditioned by the type of activity developed in the project. Thus, joint performance will be higher as projects have a greater immediacy in their applicability (exploitation projects) compared with the less applied projects which generally offer long term results (exploration projects).

Regarding the type of partners and the size of networks, our results are consistent with prior research on the structural characteristics of joint R\&D projects. As noted in the works of Dyer and Nobeoka [27], and Gilsing et al. [29] exploration networks, from a structural viewpoint, are formed by a high number of relatively homogeneous partners, while the key characteristics of exploitation projects are the low number and the heterogeneity of partners. Such features derive from the project's objective, as March [26] argued. Thus exploitation projects involve the use of existing information to improve efficiency and returns from present strategies and competencies. Therefore, following Dyer and Nobeoka [27], it is necessary in exploitation projects for both users and sources of information to take part. Thus, universities, research centres and firms are common partners in these types of projects [72]. In addition, Moulin [71] suggested that immediacy in the implementation of results has a direct impact on the number of partners taking part in these applied projects. He argued that if the number of partners increases, the relationship contribution vs. payoff decreases which has a negative impact on the project performance. Also, the largest number of partners brings about an increase in the likelihood that opportunistic behaviour will occur [44], [33] and will consequently produce a negative effect on project performance. Regarding exploration projects, according to Gilsing et al. [29] their objective is the creation of technological knowledge through a constant search for new opportunities, therefore the size and the homogeneity of the network have a positive incidence in the seeking and processing of information [28].

Concerning the results of network density and intensity of ties, the concavity of the curve gives new empirical evidence on the optimisation of interrelations in joint projects. Thus, our results, in accordance with Rowley et al. [48] and Hagedoorn et al. [3], highlight the importance of strong ties 
and high interaction among partners in exploitation projects (dense networks), whereas weak ties and sparse networks are the characteristics of arrangements in exploration networks. Another aspect is that our results complement the conclusions of previous researchers who pointed out the negative aspects associated with high cohesion networks [55], [54]. Accordingly, high cohesion may produce high conflict levels between partners and it diminishes the potential to explore new alternatives. Similarly, our results add empirical evidence that the weak interaction between partners may involve governance problems and clustering [29].

\subsection{Theoretical implications}

Our empirical analysis improves our understanding of joint R\&D projects in three ways. First, it extends the project management literature, showing empirical evidence on the performance of exploration and exploitation joint R\&D projects. Our results confirm that the typology of partners, network size, and cohesion have great impact on project results and on the efficiency perceived by partners, as well as on the contingent character of the structure with the type of R\&D project.

Second, it extends the resource-based perspective to analyse the impact of structural variables on the efficiency of joint R\&D projects. Thus, the resource-based perspective suggests that cooperation agreements are a popular way for most firms to obtain critical resources which arise not only from their own resources but also from the possibility of accessing these resources through cooperation. Eisenhardt and Schoonhoven [11] identify the heterogeneity of resources, where not all firms possess the same amount or kinds of resources, as a precondition for competitive advantage. Therefore, our results are consistent with the logic of the resource-based perspective and complement previous research, highlighting two sources of heterogeneity: one which derives from the different typology of partners (as in the case of exploitation projects) and another which stems from the diversity of information resulting from the higher number of partners (as in the case of exploration projects).

Third, our research extends social capital theory to analyse the impact of structural variables on the performance of joint R\&D projects. Social exchange theory emphasizes that interactions between 
partners provide social capital through the partnership which has an impact on the performance of such projects. Thus, Denison et al. [50] suggested the complex nature of the relationship between social capital and the efficiency of joint projects, and more recently other researchers have explained their nonlinear inverted U-shaped relationship [55], [54]. Therefore, our results are consistent with the logic of social exchange theory, and complement previous research adding new empirical evidence on the nonlinear and contingent nature existing between interaction and project performance, allowing the consideration of the optimisation of interactions in the network.

\subsection{Managerial implications}

There are several practical conclusions we can reach with this paper. For managers, our study offers findings that should make partners more informed of networking process. Project managers need to suitably design the partnership in terms of number and type of partners and interactions, taking into account the technological objectives of the project. In this sense, the opportunities provided by networks are also positional, derived from the density and intensity of ties with partners in the project. We believe our analysis identifies interesting aspects for practitioners seeking to maximize the upside of joint $R \& D$ projects' membership. Thus, the reduced number of heterogeneous partners in exploitation projects cannot be inferred to exploration projects. In a similar way, the importance of the network density and the intensity of contacts in exploitation projects cannot be generalised to exploration projects, in which a moderate interaction between partners is a key aspect in the achievement of a better performance. Finally, the analysis developed here has implications for policymakers. In general, knowledge of the conditions under which networks operate allows governments to better prepare and support domestic enterprises and institutions when they take part in joint $\mathrm{R} \& \mathrm{D}$ projects. From a policy point of view, if joint $\mathrm{R} \& \mathrm{D}$ projects of domestic firms and institutions play crucial roles in innovation and competitiveness, governments need to actively nurture these partnerships. The results of our analysis support the view that relationships among partners in joint $R \& D$ projects are characterized by their heterogeneity. To generalize about these relationships, and develop policies in support of collaboration, is important to take into account the differences for 
both set of projects; in general, current policies are mainly directed to creating incentives for firms and institutions to participate in international joint R\&D projects, with no acknowledgement that patterns of collaboration will affect project performance. This paper provides strong evidence that structural variables are very important in explaining project performance.

\subsection{Limitations and future research}

This study has some limitations that need to be addressed in future research. First, our study only investigates a limited number of structural variables of joint $R \& D$ projects. As proposed in social network research, there are other variables that may affect project performance from the point of view of partners at both a network and dyadic level, such as clustering, robustness, centrality or closeness. Further research should be conducted to test the validity of these variables and their impact on the explanation of joint project performance.

Second, our results provide evidence on the performance of both exploration and exploitation joint R\&D projects, but they are limited to only one sector, biotechnology. Future research efforts could extend similar inquiries to other contexts of projects, examining the conditions under which interactions between these structural variables may result in superior performance.

Third, this study investigates only the structural configuration as an explanation of the mechanism of joint performance, leaving some other aspects unexplored, i.e. the social structures that shape the technological outcomes and network behaviour. Future research could continue the studies of these issues offering new insights into how additional variables, such as trust, confidence and relational norms, affect the performance of joint projects.

Fourth, the cross-sectional nature of the information gathered in this study constrains the analysis of temporal effects. Longitudinal data would have been useful to determine whether the effect of size, diversity and interactions in the network was a short-term effect or if constitute an enduring process over time [73]. However, it has been also argued that the potential reliability shortcomings of longitudinal data may cause flawed results [74], mainly due to the unlikely sustained availability and cooperation required of key informants [75]. 
Despite these limitations, the analysis suggested in this paper has identified the synergies between size, partner type, network density and intensity of ties with the focus on joint R\&D projects. Our study has investigated the interplay of those variables depending on the exploration vs. exploitation nature of joint $R \& D$ projects, which has enhanced our understanding of structural aspects in the performance of this type of partnership, adding novel information on the operation of such projects.

\section{References}

[1] F. J. Contractor, P. Lorange, The growth of alliances in the knowledge-based economy. In F. J. Contractor, P. Lorange (Eds), Cooperative Strategies and Alliances. Oxford: Elsevier, 2002, pp. $3-24$.

[2] P. Kale, H. Singh. Managing strategic alliances: what do we know now, and where do we go from here? Academy of Management Perspectives 23 (2009) 45-62.

[3] J. Hagedoorn, A. Link, N. Vonortas. Research partnerships. Research Policy 29 (2000) 567-586.

[4] M. Wang. Exploring potential R\&D collaborators with complementary technologies: The case of biosensors. Technological Forecasting and Social Change 79 (2012) 862-874.

[5] L.G. Branstetter, M. Sakakibara. When do research consortia work well and why? Evidence from Japanese Panel Data. American Economic Review 92 (2002) 143-159.

[6] B.R. Koka, J.E. Prescott. Strategic alliances as social capital: a multidimensional view. Strategic Management Journal 23 (2002) 795-816.

[7] R. W. Rycroft. Does cooperation absorb complexity? Innovation networks and the speed and spread of complex technological innovation. Technological Forecasting and Social Change 74 (2007) 565-578.

[8] Ch. Dhanaraj, A. Parkhe. Orchestrating innovation networks. Academy of Management Review 31 (2006) 659-669.

[9] S. Pek-Hooi, E.B. Roberts. Technology alliances and networks: an external link to research capability. IEEE Transactions on Engineering Management 52 (2005) 419-428.

[10] R. Veugelers. Alliances and the pattern of cooperative advantages. International Business Studies 4 (1995) 213-231.

[11] K.M. Eisenhardt, C.B. Schoonhoven. Resource-based view of strategic alliance formation: Strategic and social effects in entrepreneurial firms. Organization Science 7 (1996) 136-150. 
[12] J. Lowe, P. Taylor. R\&D and technology purchase trough license agreements: complementary strategies and complementary assets. R\&D Management 28 (1998) 263-278.

[13] M. Fritsch, R. Lukas. Who co-operates on R\&D? Research Policy 30 (2001) 297-312.

[14] B.S. Tether. Who co-operates for innovation, and why. An empirical analysis. Research Policy 31 (2002) 947-967.

[15] L. Miotti, F. Sachwald. Co-operative R\&D: why and with whom? An integrated framework of analysis. Research Policy 32 (2003) 1481-1499.

[16] D. Lavie, L. Rosenkopf. Balancing exploration and exploitation in alliance formation. Academy of Management Journal 49 (2006) 797-818.

[17] M.S. Granovetter. The strength of weak ties. American Journal of Sociology 78 (1973) 13601380.

[18] J.C. Coleman. Foundations of Social Theory. Cambridge, MA: Harvard University Press, 1990.

[19] E. Uehara. Dual exchange theory, social networks and informal Social Support. American Journal of Sociology 96 (1990) 521-557.

[20] B. Uzzi. The sources and consequences of embeddedness for the economic performance of organizations. American Sociological Review 61 (1996) 674-698.

[21] B. Kogut. The network as knowledge: generative rules and the emergence structure. Strategic Management Journal 21 (2000) 405-425.

[22] R.S. Burt. Structural holes and good ideas. American Journal of Sociology 110 (2004) 349-399.

[23] P.S. Adler, S.W. Kwon. Social Capital: Prospects for a new concept. Academy of Management Review 27 (2002) 17-40.

[24] P. Moran. Structural vs. relational embeddedness: Social capital and managerial performance. Strategic Management Journal 26 (2005) 1129-1151.

[25] S.P. Borgatti, D.S. Halgin. On network theory. Organization Science 22 (2011) 1168-1181.

[26] J. G. March. Exploration and exploitation in organizational learning. Organization Science 2 (1991)71-87.

[27] J.H. Dyer, K. Nobeoka. Creating and managing a high performance knowledge sharing network: the case of Toyota. Strategic Management Journal 2 (2000) 345-367.

[28] V.A. Gilsing, B. Nooteboom. Exploration and exploitation in biotechnology. Research Policy 35 (2006) 1-23.

[29] V. Gilsing, B. Nooteboom, W. Vanhaverbeke, G. Duysters, A. van den Oord. Network Embeddedness and the Exploration of Novel Technologies: Technological Distance, Betweenneess Centrality and Density. Research Policy 37 (2008) 1717-1731. 
[30] S. Rodan, C. Galunic. More than network structure: how knowledge heterogeneity influences managerial performance and innovativeness. Strategic Management Journal 25 (2004) 541-562.

[31] J. Zhang, Ch. Baden-Fuller. The Influence of Technological Knowledge Base and Organizational Structure on Technology Collaboration. Journal of Management Studies 47 (2010) 679-704.

[32] A. O' Sullivan. Dispersed collaboration in a multi-firm, multi-team product-development project. Journal of Engineering and Technology Management 20 (2003) 93-116.

[33] H. Hoang, F. Rothaermel. The effect of general and partner-specific alliance experience on joint R\&D project performance. Academy of Management Journal 48 (2005) 332-345.

[34] Ch. Scott-Young, D. Samson. Project success and project team management: Evidence from capital projects in the process industries. Journal of Operations Management 26 (2008) 749-766.

[35] O.E. Williamson. The Theory of the Firm as Governance Structure: From Choice to Contract. The Economic Perspective 16 (2002) 171-196.

[36] B. Lawson, B. Tyler, P.D. Cousins. Antecedents and consequences of social capital on buyer performance improvement. Journal of Operations Management 26 (2008) 446-460.

[37] R.M. Emerson. Power-dependence relations. American Sociological Review 27 (1962) 31-41.

[38] R.S. Burt. Structural Holes: The Social Structure of Competition. Cambridge, MA: Harvard University Press, 1992.

[39] M. Gallstedt. Working conditions in projects: perceptions of stress and motivation among project team members and project managers. International Journal of Project Management 21 (2003) 449-455.

[40] A. Gupta, K. Smith, C. Shalley. The interplay between exploration and exploitation. Academy of Management Journal 49 (2006) 693-706.

[41] A. Oke, M. Idiagbon-Oke, F. Walumbwa. The relationship between brokers' influence, strength of ties and NPD project outcomes in innovation-driven horizontal networks. Journal of Operations Management 26 (2008) 571-589.

[42] P. Faria, F. Lima, R. Santos. Cooperation in innovative activities: the importance of partners. Research Policy 39 (2010) 1082-1092.

[43] J. Nahapiet, S. Ghoshal. Social Capital, Intellectual Capital and the Organizational Advantage. Academy of Management Review 23 (1998) 242-266.

[44] R. Gulati. Alliances and networks. Strategic Management Journal 19 (1998) 293-317.

[45] B.H. Hall, A. Link, J.T. Scott. Barriers Inhibiting Industry from Partnering with Universities: Evidence from the Advanced Technology Program. The Journal of Technology Transfer 26 (2001) 87-98. 
[46] M.S. Granovetter. Economic action and social structure: the problem of embeddedness. American Journal of Sociology 91 (1985) 481-510.

[47] S.P. Borgatti, P.C. Foster. The Network Paradigm in Organizational Research: A Review and Typology. Journal of Management 29 (2003) 991-1013.

[48] T. Rowley, D. Behrens, D. Krackhardt. Redundant governance structures: an analysis of structural and relational embeddedness in the Steel and Semiconductor Industries. Strategic Management Journal 21 (2000) 369-386.

[49] M.S. Granovetter. Problems of explanation in economic sociology. In N. Nohria, R.G. Eccles (Eds), Networks and Oganizations, Boston Ma: Harvard Business School Press, 1992, 25-56.

[50] D.R. Denison, R. Hooijberg, R.E. Quinn. Paradox and performance: towards a theory of behavioral complexity in managerial leadership. Organization Science 6 (1995) 524-540.

[51] G.N. Sctock, M.V. Tatikonda. A typology of project-level technology transfer processes. Journal of Operations Management 18 (2000) 719-737.

[52] N. Arranz, J.C.Fdez. de Arroyabe. Governance structures in R\&D networks: An analysis in the European context. Technological Forecasting and Social Change 74 (2007) 645-662.

[53] B. McEvily, A. Zaheer . Bridging ties: a source of firm heterogeneity in competitive capabilities. Strategic Management Journal 20 (1999) 1133-1156.

[54] F.X. Molina-Morales, M.T. Martinez-Fernandez. Too much love in the neighborhood can hurt: how and excess of intensity and trust in relationships may produce negative effect on firms. Strategic Management Journal 30 (2009) 1013-1023.

[55] M.A. McFadyen, A.A. Jr. Cannella. Social capital and knowledge creation: diminishing returns of the number and strength of exchange relationships. Academy of Management Journal 47 (2004) 735-746.

[56] L. Poppo, T. Zenger. Do Formal Contracts and Relational Governance Function as Substitutes or Complements? Strategic Management Journal 23 (2002) 707-725.

[57] N. Arranz, J.C. Fdez de Arroyabe. Effect of Formal Contracts, Relational Norms and Trust on Performance of Joint Research and Development Projects. British Journal of Management 23 (2012) 575-588.

[58] D.A. Dillman. Mail and Telephone Surveys: The Total Design Method. New York, NY: John Wiley \& Sons, 1978.

[59] N.S. Contractor, P. Monge. Theories of communication networks. New York: Oxford University Press, 2003. 
[60] N.S. Contractor, S. Wasserman, K. Faust. Testing multitheoretical, multilevel hypotheses about organizational networks: an analytic framework and empirical example. Academy of Management Review 31 (2006) 681-703.

[61] V. Chiesa, R. Manzini. Organizing for technological collaborations: a managerial perspective. $R \& D$ Management 28 (1998) 199-212.

[62] D.J. Brass, K.D. Butterfield, B.C. Skaggs. Relationships and unethical behavior: A social network perspective. Academy of Management Review 23 (1998) 14-31.

[63] S.P. Borgatti, R. Cross. A relational view of information seeking and learning in social networks. Management Science 49 (2003) 432-445.

[64] R. Reagans, B. McEvily. Network structure and Knowledge transfer: The effects of cohesion and ranges. Administrative Science Quarterly 48 (2003) 240-267.

[65] R. Krishnan, X. Martin. When Does Trust Matter to Alliance Performance? Academy of Management Journal 29 (2006) 401-423.

[66] P. Olk. Evaluating strategic alliance performance. In F.J. Contractor, P. Lorange(Eds.), Strategies and alliances. Kidlington, UK, Elsevier, 2002.

[67] P. Hornik, M. Stinchcombe, H. White. Multilayer feed forward networks are universal approximators. Neural Networks 8 (1989) 359-366.

[68] J. Ciurana, G. Quintana, M.L. Garcia-Romeu. Estimating the cost of vertical high-speed machining centres, a comparison between multiple regression analysis and the neural approach. International Journal of Production Economics 115 (2008) 171-178.

[69] J. Hagedoorn. Understanding the rationale of strategic technology partnering: interorganizational modes of cooperation and sectorial differences. Strategic Management Journal 14 (1993) 371385.

[70] R. Grewal, G.L. Lilien, G. Mallpragada. Location, location, location: how network embeddedness affects Project success in open source systems. Management Science 52 (2006) 1043-1056.

[71] H. Moulin. Cooperative microeconomics. A game theoretic introduction. Wheatsheaf, Harvester: Prentice Hall, 1995.

[72] B. Eom, K. Lee. Determinants of industry-academy linkages and, their impact on firm performance: The case of Korea as a latecomer in knowledge industrialization. Research Policy 39 (2010) 625-639.

[73] S.D. Jap. Pie-expansion efforts: Collaboration processes in buyer-supplier relationships. Journal of Marketing Research 36 (1999) 461-475. 
[74] S.D. Jap, S. Ganesan. Control mechanisms and the relationship life cycle: Implications for safeguarding specific investments and developing commitment. Journal of Marketing Research 37 (2000) 227-245.

[75] J.C. Anderson. Relationships in business markets: Exchange episodes, value creation, and their empirical assessment. Journal of the Academy of Marketing Science 23 (1995)346-350. 


\section{Table 1.}

Descriptive statistics, mean, standard deviation, Cronbach's alpha and bivariate correlation for all pairs of variables

\begin{tabular}{lcccccccc}
\hline Variables & Mean & S.D. & $\boldsymbol{\alpha}$ & $\mathbf{1}$ & $\mathbf{2}$ & $\mathbf{3}$ & $\mathbf{4}$ & $\mathbf{5}$ \\
\hline Joint exploration projects $(N=163)$ & & & & & & & & \\
1. Joint performance & 2.7 & 0.50 & 0.739 & 1.000 & 0.320 & 0.118 & -0.055 & -0.174 \\
2. Network size & 9.8 & 2.02 & - & & 1.000 & 0.025 & -0.009 & 0.089 \\
3. Partners' dispersion degree & 0.6 & 0.18 & - & & & 1.000 & 0.053 & 0.096 \\
4. Network density & 3.2 & 0.96 & - & & & & 1.000 & 0.281 \\
5. Tie intensity & 2.1 & 1.01 & 0.877 & & & & & 1.000 \\
Joint exploitation projects $(N=208)$ & & & & & & & & \\
1. Joint performance & 3.7 & 1.56 & 0.802 & 1.000 & -0.227 & -0.185 & 0.291 & 0.324 \\
2. Network size & 4.9 & 1.04 & - & & 1.000 & 0.010 & -0.034 & -0.097 \\
3. Partners' dispersion degree & 0.2 & 0.15 & - & & & 1.000 & 0.055 & 0.032 \\
4. Network density & 4.1 & 0.33 & - & & & & 1.000 & 0.348 \\
5. Tie intensity & 4.7 & 0.61 & 0.854 & & & & & 1.000 \\
\hline
\end{tabular}

Table 2.

Structural model for exploration projects

\begin{tabular}{lcccccc}
\hline \multicolumn{1}{c}{ Variables } & \multicolumn{3}{c}{ Exploration Projects } \\
\cline { 2 - 7 } & \multicolumn{2}{c}{ M1 } & \multicolumn{2}{c}{ M2 } & \multicolumn{2}{c}{ M3 } \\
\cline { 2 - 7 } & $\begin{array}{c}\text { Standarized } \\
\text { effect }\end{array}$ & t-value & $\begin{array}{c}\text { Standarized } \\
\text { effect }\end{array}$ & t-value & $\begin{array}{c}\text { Standarized } \\
\text { effect }\end{array}$ & t-value \\
Size of network & $0.774^{* * *}$ & 6.186 & - & - & $0.725^{* * *}$ & 6.509 \\
Degree of partners dispersion & $0.119^{*}$ & 2.219 & - & - & $0.137^{*}$ & 2.104 \\
Intensity of ties & - & - & $-0.192^{*}$ & 2.193 & $-0.157^{*}$ & 2.118 \\
Network Density & - & - & $-0.287^{*}$ & -2.609 & $-0.201 *$ & -2.391 \\
\hline
\end{tabular}

M1: $\chi^{2}=92.011 ;$ d.f. $=69 ; \mathrm{p}<0.01 ; \mathrm{IFI}=0.91 ; \mathrm{TLI}=0.91 ; \mathrm{GFI}=0.92 ; \mathrm{CFI}=0.97 ; \mathrm{RMR}=0.05$ and RMSEA=0.05 M2: $\chi^{2}=93.339 ;$ d.f. $=75 ; \mathrm{p}<0.01 ;$; IFI=0.90; TLI=0.88; GFI=0.90; $\mathrm{CFI}=0.95 ; \mathrm{RMR}=0.05$ and RMSEA=0.06 M3: $\chi^{2}=107.502 ;$ d.f. $=81 ; p<0.01 ; \mathrm{IFI}=0.91 ; \mathrm{TLI}=0.91 ; \mathrm{GFI}=0.90 ; \mathrm{CFI}=0.97 ; \mathrm{RMR}=0.05$ and $\mathrm{RMSEA}=0.04$ $* \mathbf{p}<.05 ; * * \mathbf{p}<.01 ; * * * \mathbf{p}<.001$

Table 3.

Structural model for exploitation projects

\begin{tabular}{lcccccc}
\hline \multicolumn{1}{c}{ Variables } & \multicolumn{3}{c}{ Exploitation Projects } \\
\cline { 2 - 7 } & \multicolumn{2}{c}{ M1 } & \multicolumn{2}{c}{ M2' } & M3' \\
\cline { 2 - 7 } & $\begin{array}{c}\text { Standarized } \\
\text { effect }\end{array}$ & t-value & $\begin{array}{c}\text { Standarized } \\
\text { effect }\end{array}$ & t-value & $\begin{array}{c}\text { Standarized } \\
\text { effect }\end{array}$ & t-value \\
\cline { 2 - 7 } Size of network & $-0.402^{* * *}$ & -5.995 & - & - & $-0.397 * * *$ & -5.020 \\
Degree of partners dispersion & $-0.127 * *$ & -3.672 & - & - & $-0.105^{*}$ & -2.911 \\
Intensity of ties & - & - & $0.714^{* * *}$ & 6.721 & $0.702 * * *$ & 6.105 \\
Network Density & - & - & $0.609 * * *$ & 6.138 & $0.591^{* * *}$ & 5.977
\end{tabular}

M1: $\chi^{2}=118.106 ;$ d.f. $=84 ; \mathrm{p}<0.01 ; \mathrm{IFI}=0.91 ; \mathrm{TLI}=0.90 ; \mathrm{GFI}=0.92 ; \mathrm{CFI}=0.93 ; \mathrm{RMR}=0.04$ and RMSEA=0.06 M2: $\chi^{2}=115.187 ;$ d.f. $=87 ; \mathrm{p}<0.01 ; ; \mathrm{IFI}=0.90 ; \mathrm{TLI}=0.90 ; \mathrm{GFI}=0.92 ; \mathrm{CFI}=0.91 ; \mathrm{RMR}=0.06$ and RMSEA $=0.05$ M3: $\chi^{2}=120.143$; d.f. $=90 ; \mathrm{p}<0.01 ;$; IFI=0.93; TLI=0.92;GFI=0.91; $\mathrm{CFI}=0.93 ; \mathrm{RMR}=0.05$ and $\mathrm{RMSA}=0.06$ $* \mathbf{p}<.05 ; * * \mathbf{p}<.01 ; * * * \mathbf{p}<.001$ 


\section{Table 4.}

Number of layers and number of neurons per hidden layer experimentation

\begin{tabular}{lll}
\hline $\begin{array}{l}\text { Experimental } \\
\text { numbers }\end{array}$ & $\begin{array}{l}\text { No. of hidden } \\
\text { layers }\end{array}$ & $\begin{array}{l}\text { No. of neurons per } \\
\text { layer }\end{array}$ \\
\hline $1-6$ & 1 & $4,5,6,8,10,11$ \\
$7-12$ & 2 & $4,5,6,8,10,11$ \\
$13-18$ & 3 & $4,5,6,8,10,11$
\end{tabular}

Activation functions: sigmoid and linear functions; log-sigmoid and linear functions, sigmoid and sigmoid functions, log-sigmoid and log-sigmoid functions

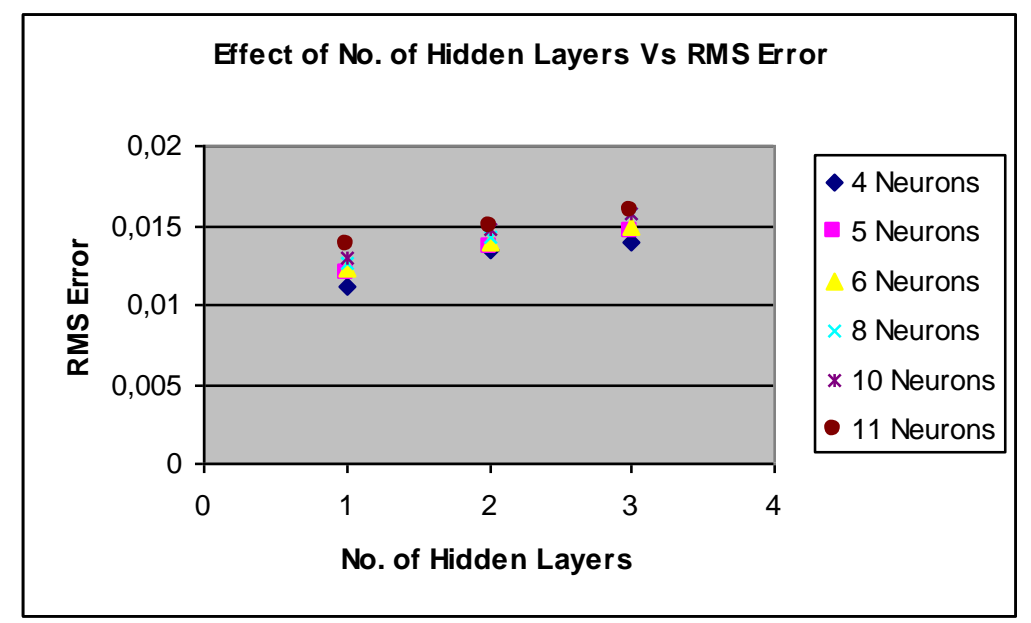

Architecture: ANN- MLP, with sigmoid and linear functions as activation functions.

Fig. 1. Effect of the number of hidden layers vs. Root Mean Square error in exploitation projects

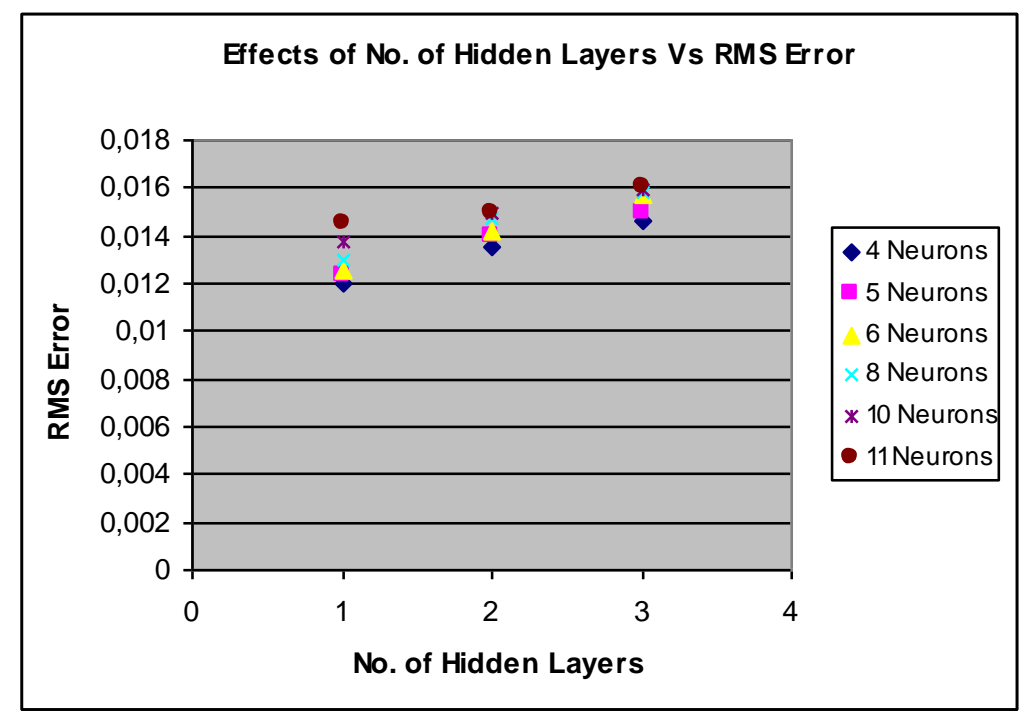

Architecture: ANN-MLP, with sigmoid and linear functions as activation functions.

Fig. 2. Effect of the number of hidden layers vs. Root Mean Square error in exploration projects 


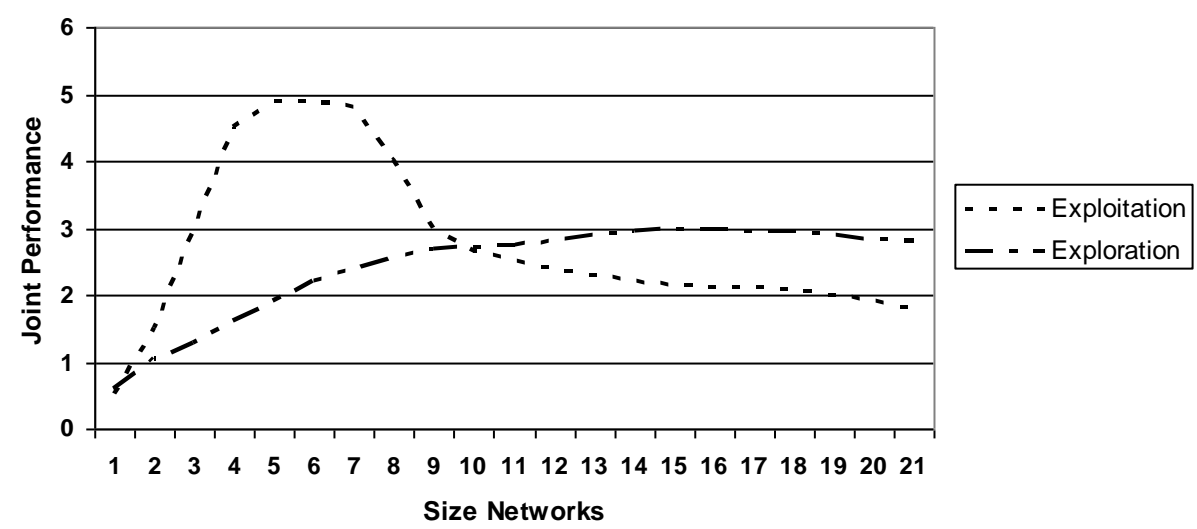

Fig. 3. Effect of Network Size on Joint Performance

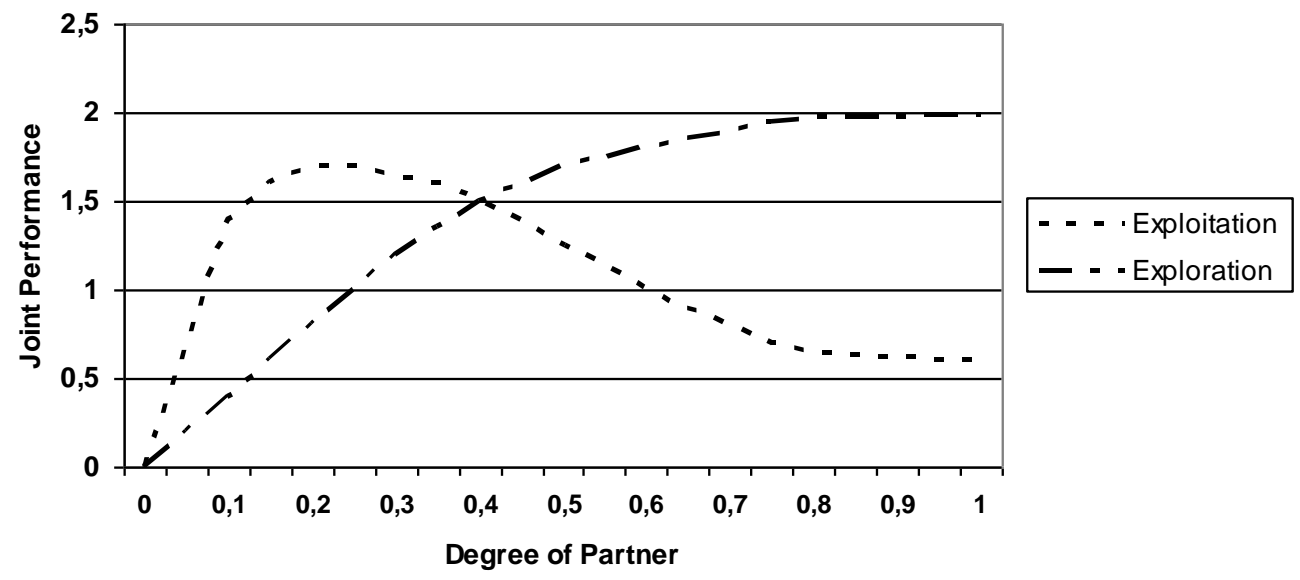

Fig. 4. Effect of Degree of Partners Dispersion on Joint Performance

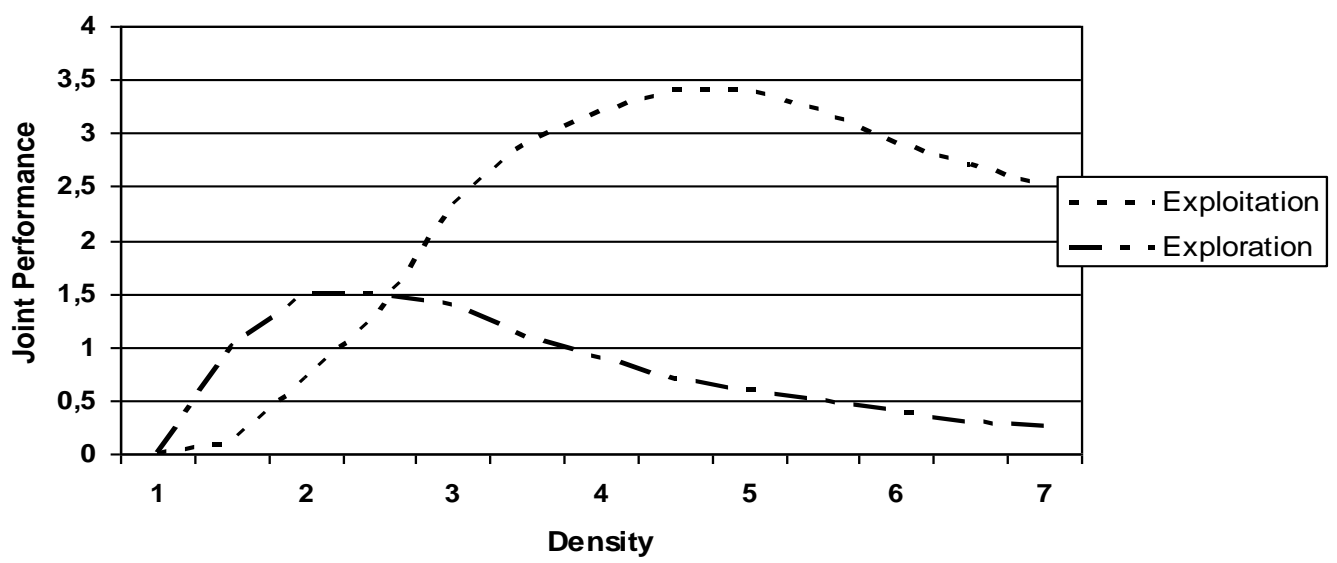

Fig. 5. Effect of Density on Joint Performance 


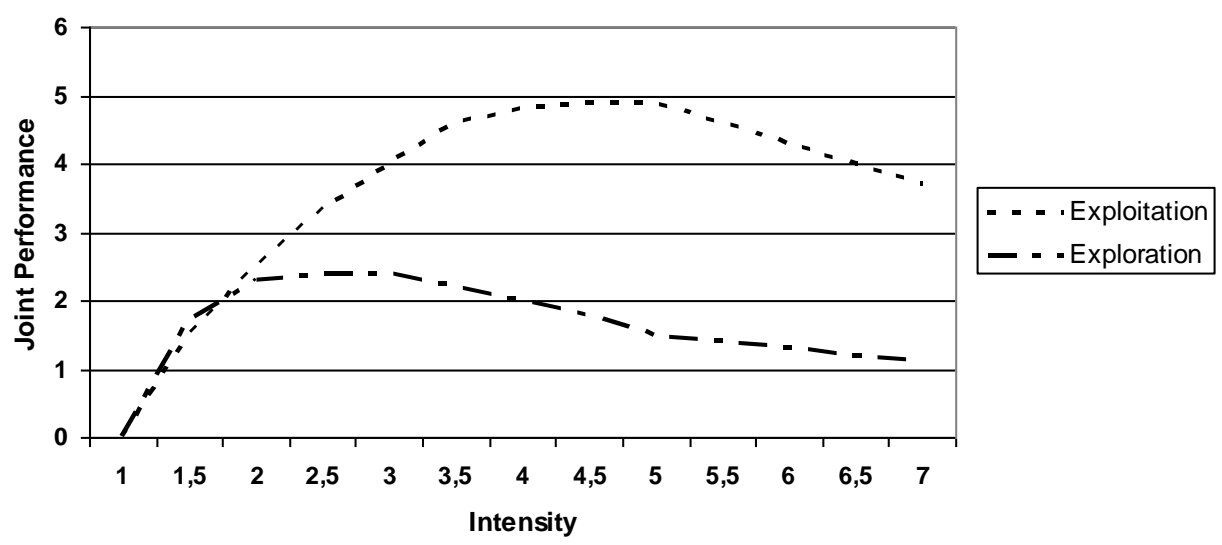

Fig. 6. Effect of Intensity on Joint Performance 